\title{
Review Article \\ Neural Pathways Conveying Novisual Information to the Visual Cortex
}

\author{
Wen Qin ${ }^{1}$ and Chunshui Yu ${ }^{1,2}$ \\ ${ }^{1}$ Department of Radiology and Tianjin Key Laboratory of Functional Imaging, Tianjin Medical University General Hospital, \\ Tianjin 300052, China \\ ${ }^{2}$ School of Medical Imaging, Tianjin Medical University General Hospital, Tianjin 300052, China \\ Correspondence should be addressed to Chunshui Yu; chunshuiyu@tijmu.edu.cn
}

Received 31 March 2013; Accepted 22 May 2013

Academic Editor: Małgorzata Kossut

Copyright (C) 2013 W. Qin and C. Yu. This is an open access article distributed under the Creative Commons Attribution License, which permits unrestricted use, distribution, and reproduction in any medium, provided the original work is properly cited.

\begin{abstract}
The visual cortex has been traditionally considered as a stimulus-driven, unimodal system with a hierarchical organization. However, recent animal and human studies have shown that the visual cortex responds to non-visual stimuli, especially in individuals with visual deprivation congenitally, indicating the supramodal nature of the functional representation in the visual cortex. To understand the neural substrates of the cross-modal processing of the non-visual signals in the visual cortex, we firstly showed the supramodal nature of the visual cortex. We then reviewed how the nonvisual signals reach the visual cortex. Moreover, we discussed if these non-visual pathways are reshaped by early visual deprivation. Finally, the open question about the nature (stimulus-driven or top-down) of non-visual signals is also discussed.
\end{abstract}

\section{Introduction}

The visual cortex has been traditionally considered as a stimulus-driven, unimodal system with a hierarchical organization, in which the early visual areas (V1, V2) tune to general features while the higher-tier ones $(\mathrm{V} 3 \mathrm{~A}, \mathrm{~V} 4 \mathrm{v}, \mathrm{V} 7$, $\mathrm{hMT}+$, and V8) respond selectively to the specific features of a visual stimulus [1-5]. Two parallel visual streams have been proposed to generalize the hierarchical organization of the visual processing [6-8]. The dorsal stream or "where" pathway serves to analyze visual spatial information about object location, motion, and visuomotor planning. In this pathway, visual signals are conveyed to the posterior parietal cortex through the dorsal part of the visual cortex (such as the V3d, V3A, V7, and hMT+) and finally reach the prefrontal cortex. The ventral stream or "what" pathway has been associated with the processing of form, object identity, and color. This pathway conveys visual signals along the ventral part of visual cortex (such as VP, V4, and V8), the inferior temporal (IT) areas, and finally to the prefrontal cortex.

The structural and functional organization of the visual areas is supposed to develop through a combination of genetic instruction [9-11] and experience-dependent refinement $[12,13]$. The role of visual experience in the development of the visual areas is supported by a large number of neuroimaging studies revealing that the visual areas of congenitally blind (CB) and early blind (EB) subjects have increased cortical thickness [14-17], local brain spontaneous activity [18], metabolism, and blood flow [19-22] and decreased regional volume [23-25], white matter integrity [26, 27], anatomical network efficiency $[28,29]$, and altered restingstate functional connectivity (rsFC) [30,31]. Moreover, converging evidence suggests that both the early and higher-tier visual areas in CB subjects are recruited during performing a variety of tasks given through nonvisual sensory modalities, as detailed in previous reviews [32-36].

However, the notion of the visual cortex as a unimodal system molded only by visual experience has recently been challenged because the visual cortex of both the sighted controls (SC) and the CB responded to a variety of nonvisual perceptive stimuli, including tactile, auditory, and olfactory. Furthermore, the visual cortex of the $\mathrm{CB}$ was also involved in cognitive processes, such as linguistic processing, working memory, and attention. Although the extent and magnitude of the activation in the visual areas depend on the tasks and 
subjects' characteristics $[37,38]$, the coactivation of several visual areas by nonvisual tasks in SC and CB highly indicates that the development of the functional organization of these visual areas does not require visual experience.

The main topic of this review is to elucidate how the nonvisual signals recruit the visual cortex. We firstly provide evidence if the visual cortex is supramodal in nature, and then we reviewed how the nonvisual signals reach the visual cortex. Next, we discussed if these nonvisual pathways are reshaped by early visual deprivation. Finally, we also discussed about the nature (stimulus-driven or top-down) of nonvisual signals.

\section{The Supramodal Nature of Visual Cortex}

\subsection{Cross-Modal Processing of Nonvisual Signals in the Visual Cortex in Sighted Subjects}

2.1.1. Tactile Stimuli Activate the Visual Cortex in Sighted Subjects. Unimodal theory supposes that the visual cortex is specifically allocated to process visual stimuli in sighted people; however, this hypothesis has recently been challenged. Using the positron emission tomography (PET), Sathian et al. first reported that the extrastriate area close to the parietooccipital fissure (V6) was activated during discrimination of grating orientation compared with discrimination of grating groove width, suggesting this visual area is recruited in the processing spatial information of tactile signals [39]. To further confirm that the occipital area is functionally involved in nonvisual processing, the transcranial magnetic stimulation (TMS) technique was used to transiently disrupt the functioning of this area. The authors found impaired tactile discrimination of grating orientation after exerting TMS on this occipital area and concluded that this occipital area is really functionally involved in tactile spatial perception [40]. Since then, many studies have reported the involvement of visual areas in a series of tactile processing, including the hMT+ complex for tactile motion perception [37, 41] and the ventral visual pathway for tactile object discrimination [42-49]. It is interesting to note that the hMT+ is capable of processing motion-related information even when the stimulus is delivered to the tongue [50]. Furthermore, several studies using both visual and tactile stimuli showed that these two modalities drive the same visual areas for motion and object processing, supporting the cross-modal involvement of visual areas in the abstract representation of the concepts of objects, space, and motion [38, 42].

2.1.2. Auditory Stimuli Activate the Visual Cortex in Sighted Subjects. The cross-modal recruitment of the visual cortex has also been reported in auditory domain. As early as 1972 , Morrell found that up to $41 \%$ of recorded neurons in extrastriate cortex of adult cats were modulated by both visual and auditory stimuli and that the receptive fields for both responses typically overlapped in space [51]. Recent studies in humans have also provided evidence of occipital activation in auditory processing $[52,53]$. For example, the hMT+ complex was activated in sighted subjects while listening to auditory motion stimuli $[52,54,55]$. In accordance with the neuroimaging findings, several TMS studies showed that transient disruption of the specific occipital regions can impair the auditory perception in sighted subjects, such as inhibition of the extrastriate cortex induced a systematic error in auditory spatial perception [56], and disruption of the dorsal extrastriate cortex impaired the sound localization $[57,58]$. The TMS evidence supports that the visual cortex is involved in spatial hearing in sighted subjects. It is also interesting to note that the visual cortex in sighted subjects cannot only percept the sound itself but also response to abstract auditory information such as action sounds [59].

2.2. Cross-Modal Processing of Nonvisual Signals in the Visual Cortex in Early Blind Subjects. Relative to the sighted subjects, cross-modal processing of nonvisual signals in the visual cortex has been more extensively reported in the $\mathrm{CB}$ and $\mathrm{EB}$ subjects when they perform nonvisual perception and high-order cognitive tasks.

2.2.1. Tactile Perception. Numerous studies reported that the visual cortex was recruited during diverse tactile tasks, such as the early and higher visual areas were activated in vibrotactile frequency discrimination [60], the hMT+ in tactile motion perception $[37,50,61]$, and the ventral visual pathway in tactile object perception [38]. The visual cortex is also involved in tactile perception of the tongue $[42,62,63]$. Using the tongue display device (TDU), a tactile-to-vision sensory substitution device that translates a visual image into electrotactile stimulation, several studies have shown that the specific visual areas were recruited to process different types of tongue tactile stimuli, such as the ventral stream for tactileform recognition [42], the hMT+ complex for tactile motion discrimination [50], and the ventral lateral occipitotemporal cortex for virtual route recognition [62]. Moreover, rTMS inhibition of the human hMT+ impaired the tactile speed discrimination, indicating that the recruitment of hMT+ is necessary for tactile motion processing [41]. Interestingly, TMS stimulation of the visual cortex can induce subjective tongue-tactile sensations in the $\mathrm{CB}$ who is proficient at the use of the TDU, which indicates that the perceptual correlate of activity in the visual cortex reflects the characteristics of its novel sensory input source [64].

2.2.2. Auditory Perception. Similar with the tactile perception, the activation of the visual cortex by auditory perception was also frequently reported in CB subjects $[54,65,66]$. In an early PET study, Weeks et al. [67] reported that the right dorsal visual cortex was activated by auditory perception task in the CB but not in the SC. This region was also activated in EB subjects by an auditory spatial processing task using a sensory substitution prosthesis translating visual information into sounds [65]. The activation pattern in EB was also confirmed by recent studies $[66,68,69]$. Accordingly, the visual areas previously considered to be involved in visual motion processing (such as the $\mathrm{hMT}+$ ) were specifically recruited in the EB by motion stimuli presented through the auditory modality $[50,54,55,70,71]$. The ventral pathway can 
be recruited to process auditory object recognition $[72,73]$ in the CB. In a recent study, Striem-Amit et al. [74] showed that the dorsal stream processed the location information, whereas the ventral stream responded to shape information via the vision-to-sound substitutes in CB subjects. The dorsal and ventral pathway recruited by auditory perception was further confirmed by electrophysiological and TMS evidence. Using ERP, several groups showed greater amplitude of the $\mathrm{N} 1$ component at the visual region in sound localization, suggesting the involvement of the visual cortex in early auditory processing in the EB [75-77]. TMS inhibition of the visual area can impair specific auditory performance in the EB $[57,78,79]$. For example, rTMS delivered to right dorsal extrastriate cortex disrupted the spatial processing of sounds in the EB [57, 78], and rTMS over the LOC can impair a EB subject's ability to identify objects [79].

2.2.3. Olfactory Sensation. In the $\mathrm{CB}$, besides auditory and tactile perception, the visual cortex was also recruited in olfactory processing [80]. In this study, a simple odor detection task, the authors found that CB subjects not only showed strong activation in the olfactory cortex, but also showed widespread activation in the visual cortex [80]. Combining earlier studies reported that superior olfactory perception in the $\mathrm{CB}[81,82]$; the recruitment of the visual cortex during odor detection suggests a preferential access of olfactory stimuli to this area in the CB.

2.2.4. Cognitive Processing. The visual cortex in EB subjects is not only involved in nonvisual perception, but also takes part in the process of higher-level cognitive tasks, such as language, attention, and working memory. Converging evidence supports the involvement of the visual cortex in language processing in the $\mathrm{CB}$ or $\mathrm{EB}$ subjects. The medial visual cortex was recruited during Braille reading [83-85] and the occipitotemporal visual areas were activated during covert verb generation in the EB $[86,87]$. Further studies reveal that the visual cortex is preferentially recruited by semantic relative to phonological processing [88], and the magnitude of fMRI activation is associated with both semantic and syntactic complexity [89]. A recent study showed that the visual word form area (VWFA), a component of the ventral stream that develops expertise for visual reading, can also process Braille reading in the EB [90]. Further evidence for the involvement of the visual cortex in language processing in the EB has been provided by a combination of task activation and functional connectivity analyses [91]. The authors found that (1) the responses of the visual regions and classic language regions across conditions were similar; (2) language sensitivity was restricted to the left visual cortex; (3) the left visual regions that responded to language had increased functional connectivity with classic language regions [91]. Besides the neuroimaging findings, in the $\mathrm{CB}$, disruption of the visual cortex by TMS or lesions impairs the performance of Braille reading and verb generation [84, 92-95].

Besides the language processing, the visual cortex that normally subserves vision is activated in the $\mathrm{CB}$ subjects when performing nonvisual attention-demanding tasks, such as spatial attention discrimination $[32,35,36]$. More importantly, the amplitude of the occipital activation in the $\mathrm{CB}$ was correlated with the spatial attention performance [66, $96,97]$. These findings suggest that the occipital activation is associated with the enhanced nonvisual attention abilities in the CB.

The visual cortex can also be activated by memory task with nonvisual stimuli or without any sensory input [98-101]. The posterior occipital region (including V1) was recruited during a verbal memory task even without real sensory stimulation in the $\mathrm{CB}$, and the activation magnitude of this region was correlated with verbal memory performance [101]. Bonino et al. reported that tactile spatial working memory task activated the dorsal extrastriate areas in the CB individuals [100]. Moreover, using three different kinds of working memory tasks (verbal, tactile, and auditory), a recent study showed that the visual cortex of the EB subjects responded to all types of stimuli [99].

\subsection{Supramodal versus Plastic Mechanisms of the Occipital} Activation. Two neural mechanisms have been proposed to explain the involvement of the visual cortex in the processing of nonvisual stimuli. One hypothesis holds that the visual cortex is supramodal in nature, which means that an occipital area relies on a common, abstract representation of the perceived stimuli irrespective of the sensory modality. Another hypothesis is the cross-modal plasticity. In the $\mathrm{CB}$ or EB, the visual cortex that normally serves to process visual input shifts to cross-modal process nonvisual information via plastic reorganization of the inner structure and function. However, the two mechanisms are not mutually exclusive, and they might coexist in the EB.

As discussed above, many pieces of evidence that showed the involvement of the visual areas in processing nonvisual inputs in both the SC and EB may support the supramodal hypothesis (see Sections 2.1 and 2.2). The cross-modal involvement of the visual cortex in processing nonvisual stimuli means that the functional specialization of the visual areas is task-dependent rather than sensory modality-dependent. Furthermore, this pattern cannot be fully explained by visual imagery [102-108] because the CB subjects who never have visual experience also show occipital response to the nonvisual stimuli $[69,80]$. The supramodal hypothesis can explain that visual experience is not necessary to develop the normal functional organization of the visual areas, which has been confirmed in a variety of previous studies on the CB $[74,90,109,110]$, because the development of the functional organization may be driven by inputs from other sensory modalities.

The cross-modal plasticity is supported by the following evidence. The CB subjects commonly showed superior performance during auditory or tactile perception than normal sighted subjects [97, 101, 111-115]. The superior performance has also been associated with the occipital activation in the CB [96, 97, 101], suggesting the hypothesis of the crossmodal plasticity. This mechanism can also be applied to explain the involvement of the visual cortex in the higherlevel cognitive tasks in the CB but not in the SC [84, 9295]. Furthermore, the plasticity mechanism may also partly 


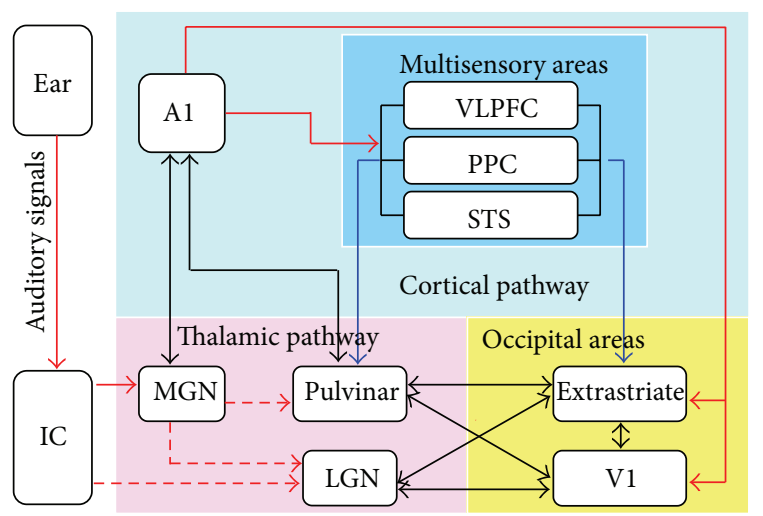

$$
\begin{aligned}
& \longrightarrow \text { Bottom-up signal } \\
& \longrightarrow \text { Top-down signal } \\
& \longleftrightarrow \text { Bidirectional signal }
\end{aligned}
$$

FIGURE 1: Schematic of neural pathways that convey auditory signals into visual areas. The solid line represents the existing connections in the normal sighted animals or human; dash line represents the rewired connections after early visual deprivation; arrows with red, blue, and black color represent the bottom-up, top-down, and bidirectional auditory signals, respectively. All these connections are confirmed by previous animal or human studies (for details see Section 3). A1: primary auditory cortex; IC: inferior colliculus; MGN: medial geniculate nucleus; LGN: lateral geniculate nucleus; PPC: post parietal cortex; STS: superior temporal cortex; VLPFC: ventral lateral prefrontal cortex; V1: primary visual cortex.

explain the increased cortical thickness [14-17], local brain spontaneous activity [18], metabolism and blood flow [19$22]$, and $\mathrm{rsFC}[30,31]$ in the EB.

Studies on the functional characteristics of the hMT+ have well described the coexistence of the two mechanisms in the EB. In sighted subjects, the hMT+ complex is segregated into an anterior part (supramodal region), that is, involved in processing both visual and tactile motion, and a posterior part (unimodal region), which is only involved in processing visual information. In the $\mathrm{EB}$, however, the entire hMT+ is involved in the representation of tactile motion, suggesting the coexistence of the supramodal (anterior part) and plastic (posterior part) mechanisms in this region. These results represent competitive interactions between visual and nonvisual inputs in the reshape of hMT+ complex $[37,116]$.

It should be noted that the improved nonvisual perception performance in the early blind subjects can also be the consequences of the experience-dependent plasticity of their auditory or somatosensory related cortices. For example, the mice that are binocularly enucleated from birth demonstrate remarkable expansion of their barrel cortex, which may be interpreted by increased usage of the whiskers after visual deprivation [117]. Cats that were deprived of vision from birth also show expanded primary somatosensory and auditory areas; furthermore, the neurons in the anterior ectosylvian visual area (AEV) that normally respond to visual stimuli are replaced by neurons of neighboring auditory ectosylvian area (AEA), which is accompanied by the improvement of auditory spatial tuning of this region than sighted controls

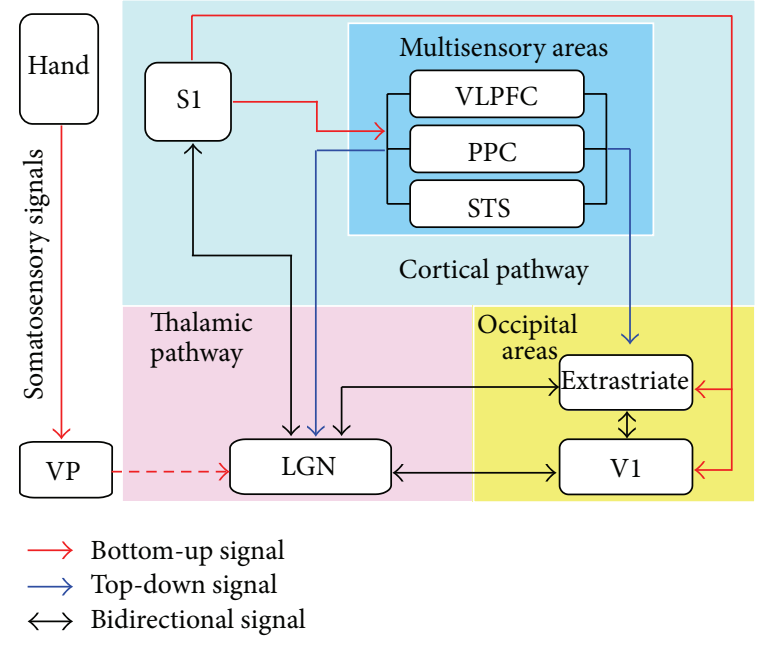

FIGURE 2: Schematic of neural pathways that convey somatosensory signals into visual areas. The solid line represents the existing connections in the normal sighted animals or human; dash line represents the rewired connections after early visual deprivation; arrows with red, blue, and black color represent the bottom-up, topdown, and bidirectional somatosensory signals, respectively. LGN: lateral geniculate nucleus; PPC: post parietal cortex; S1: primary somatosensory cortex; STS: superior temporal cortex; VLPFC: ventral lateral prefrontal cortex; V1: primary visual cortex; VP: ventral posterior nuclei.

$[118,119]$. As a result, the improved auditory/tactile perceptive performance might both be caused by the experiencedependent plasticity of the classic auditory/tactile regions with expanded cortical area, and by classic visual regions that turn to subserve the nonvisual information. Caution should be paid that some cortical regions such as the "AEV" in the congenitally blind subjects are actually replaced by expanded auditory cortices and their activation by auditory stimuli cannot be interpreted as cross-modal involvement of visual areas any more.

\section{The Candidate Pathways That Nonvisual Signals Reach the Visual Cortex}

As discussed above, much evidence supports the cross-modal processing of nonvisual signals in the visual cortex. It is then important to understand how the nonvisual sensory information reaches the occipital areas, especially in the $\mathrm{CB}$ subjects who have no visual experience about the external world. The candidate pathways include the thalamooccipital and corticooccipital pathway, which is categorized in Figures 1 and 2.

3.1. Thalamooccipital Pathway. The thalamus is an important relay that receives afferents from different sensory organs and sends efferents to the primary sensory cortex. Under normal condition, the thalamic nuclei are relay stations via which sensory information from the peripheral sensory receptors can reach the primary sensory cortex. For example, the lateral geniculate nucleus (LGN), the "visual" thalamic 
relay, mainly transfers visual signals to the primary visual cortex (V1); the medial geniculate nucleus (MGN) is the "auditory" thalamic relay that connects the inferior colliculus (IC) and the primary auditory cortex (A1); and the ventral posterior nuclei (VP) is the "somatosensory" thalamic relay that receives tactile signals and transmits them to the primary somatosensory cortex (S1) [120, 121]. Furthermore, the thalamus can also receive feedback signals from the sensory cortex [122-125] and the associate cortex [126-132] to modulate the input signals. It is hypothesized that nonvisual signals may bypass the traditional sensory pathway and "rewire" into the "visual" thalamus and project to the V1. This hypothesis is supported by the findings that the LGN receives rewired auditory projections from the inferior colliculus [133-139] and the MGN [140], receives rewired somatosensory projections from the VP $[140,141]$, and then projects efferent fibers to the visual areas in enucleated animals since birth [142].

Recent findings have shown that the LGN and its output projections to the V1 are atrophied in early blind subjects $[24,26,27]$, which seems to contradict with this hypothesis. One putative explanation is that the atrophy of the LGN and the retinofugal pathway is the consequence of the interaction between disused neurodegeneration of the "visual" part of the pathway and cross-modal plasticity of the "rewired" nonvisual part of the pathway. In fact, pervious animal experiments have shown that the visual projections to the dorsal lateral geniculate nucleus are dramatically reduced in blind animals, while the auditory projections to the same region are strengthened $[133,142]$. Another possibility is that the nonvisual signals bypass traditional retinofugal pathway (from the LGN to the V1) and pass through the pulvinaroccipital pathway [143-146], or from the LGN to the higher visual areas (such as the hMT+ and V4) [147-150]. In agreement with this interpretation, a recent fMRI study in monkeys demonstrates that direct LGN projections to the extrastriate cortex have a critical functional contribution to blindsight with V1 lesions [151]; a human study shows a direct anatomical connection between the thalamus and the hMT+ complex, that would directly convey motion information to the hMT+, thereby bypassing the V1 [147].

3.2. Corticooccipital Pathway. An alternative pathway is that the visual areas receive nonvisual sensory information through corticooccipital connections between these sensory modalities [140,152,153]. These corticooccipital connections can be further subdivided into direct corticooccipital connections and indirect polysynaptic corticooccipital connections. The former has been found between the $\mathrm{Al}$ and visual cortex in adult Mongolian gerbils [154], cats [155], primates [153, 156, 157], humans [158], and congenitally blind opossums [140], and between S1 and V1 in enucleated opossums [140]. The latter has been indicated by studies showing multisensory processing in the association cortices [159], such as the posterior parietal area (PPA) $[160,161]$, superior temporal sulcus (STS) [162-164], ventral lateral prefrontal cortex (VLPFC) [165-167], and extrastriate areas $[155,168,169]$. The dense anatomical connections between multisensory areas and both the visual and nonvisual sensory cortices have been identified in both animal and human studies $[155,159,163,170,171]$.
The corticooccipital pathway hypothesis is also supported by task-based fMRI studies $[165,172]$ and a resting-state fMRI study [173] in sighted subjects, an effective connectivity study [174], and TMS studies in sighted and EB subjects $[23,78,175,176]$. In a recent study by our group, we found the rsFC between the early visual areas and S1 was dramatically decreased, while those between the higher-tier visual areas and S1, and between the early and higher-tier visual areas, were relatively preserved or even strengthened in the CB. Our findings support the hypothesis of the indirect corticooccipital pathway mediating nonvisual sensory information to the early visual areas via the relay of higher-tier ones [17].

It should be noted that these two pathways cannot be absolutely segregated in the brain network. They are interacted with each other by feed forward and feed back projections. For example, the auditory signals can first feed forward to the $\mathrm{A} 1$ for initial processing, and then feed back to the MGN and multimodal thalamic nuclei (e.g., the pulvinar) [177], and finally project to the V1 (cortico-thalamooccipital pathway). The multisensory areas such as the PPA and VLPFC also project efferents to the multimodal thalamus (the pulvinar and medial dorsal nucleus) [127-131], so they can convey the modulated nonvisual signals to the occipital area via the thalamus (Figure 1).

The existing thalamo-cortical and corticooccipital pathways found in the normal adult animals and humans provide anatomical evidence of the supramodal nature of the visual cortex. Auditory and tactile information can be conveyed to the occipital areas through the direct and indirect connections. This anatomical connections pattern can explain the cross-modal involvement of visual cortex by nonvisual sensory tasks; furthermore, it can explain the development of a portion of the visual areas does not depend on the visual experience because inputs from other sensory modalities are sufficient to support the development of these functional patterns.

\section{Rewiring versus Unmasking of the Nonvisual Pathway after Visual Deprivation}

Two competing hypotheses have been proposed to explain the neural mechanisms of cross-modal plasticity after early visual deprivation. According to the rewiring hypothesis, cross-modal brain responses are mediated by the formation of new pathways in the sensory deprived brain. For example, after experimental destruction of the superior colliculi and the visual cortex in neonatal hamsters, the authors observed a strong projection from the retina to the A1, which can "perceive" the visual information $[178,179]$. Studies in animals have also shown that when the brain is deprived of peripheral visual input at an early age, auditory inputs are re-routed to the visual cortex via the thalamooccipital pathway $[133,139-$ 141]. However, this subcortical rewired pathway is questioned because of the lack of in vivo evidence. In contrast, there are considerable studies showed that the whole segments of retinofugal pathway, including the optic tract, the LGN, and optic radiation, suffered atrophy and loss of integrity in humans after early visual deprivation $[16,23,27]$. 
The unmasking hypothesis proposed that the loss of a sensory input induces unmasking and/or strengthening of the existing neural pathways. As discussed in Sections 3.1 and 3.2, the tactile and auditory inputs can be conveyed to the visual cortex via the existing thalamooccipital pathway or corticooccipital pathway that have been confirmed in normal adult animals and humans. Generally, these nonvisual signals can modulate the processing of visual information in sighted subjects [180]; however, they cannot induce subjective nonvisual sensations and occipital activation due to being masked by the dominant visual input $[40,64,176]$. The occasional findings of occipital processing nonvisual signals might be task-dependent that dramatically reduced the masking effects of the visual input $[40,52,55]$. However, after early visual deprivation, nonvisual processing in the visual cortex is strengthened or unmasked because of the lack of visual input. The unmasking hypothesis is also supported by the cross-modal responses after short-term visual deprivation (blindfolding). Several hours to days blindfolding resulted in rapid, reversible improvement in task performance and recruitment of the visual cortex in nonvisual processing, such as tactile discrimination [181, 182], Braille reading [183], and sound localization [184, 185]. Rapid cross-modal responses exclude the possibility that these are mediated by the establishment of new anatomical connections. This claim was also supported by sensory substitution devices (SSD) studies that the visual cortex was also involved in processing nonvisual tasks after a short period of SSD training in sighted subject $[50,72,186]$. It is possible that a short period of blindfolding and SSD training unmasks and strengthens preexisting connections between the nonvisual and the occipital cortices.

\section{Stimulus-Driven or Top-Down Control of the Nonvisual Processing in the Visual Cortex}

As shown in Figure 1, nonvisual signals can reach the visual cortex via thalamooccipital pathway, corticooccipital pathway, or combinations of these two pathways. An important but unsolved question is the nature of these nonvisual signals: stimulus-driven or top-down. The stimulus-driven signals refer to those from sensory organs or early sensory cortex, whereas the top-down signals are refer to those who came from the higher-level cortical regions. Clarifying this question can help us to understand the neural mechanisms underlying cross-modal recruitment of the visual cortex and to design appropriate interventions to improve the adaptive capacity of blind subjects to the external environments.

5.1. Stimulus-Driven Hypothesis. The following evidence supports stimulus-driven nature of the nonvisual signals that reach the visual cortex. These nonvisual signals can be conveyed from sensory organs to the visual cortex via rewired thalamic-cortical pathway [133-139] and those from the nonvisual primary sensory cortices via the direct corticooccipital connections (such as from A1 to V1) [153, 156, 157], which bypass the higher-tier "cognitive" cortex, so the inputted nonvisual signals may not be modulated and reflect the pure stimulus-driven information. The involvement of the visual cortex in nonvisual perception in both sighted $[45,46,72]$ and $\mathrm{EB}[37,42,50,61-63,66,68,69,80]$ subjects also suggests the stimulus-driven nature of these nonvisual signals because the top-down effects such as visual imagery and attention were well controlled in these studies. The event-related potentials (ERPs) studies demonstrated that the N1 component of occipital response following nonvisual stimulation was as early as the typical component of the visual perception in EB subjects [76, 77, 187]. For example, a recent report showed that the shape-selective activity in the LOC was present as early as $150 \mathrm{~ms}$ following the onset of tactile stimulation, which support the stimulus-driven somatosensory input to the LOC [187].

5.2. Top-Down Hypothesis. According to the top-down mechanism, the peripheral auditory/tactile signals are firstly modulated and refined by the higher-level cortical regions, such as the multisensory associate areas (VLPFC, PPA, and STS), and then feed back to the visual cortex through the indirect corticooccipital pathway and cortico-thalamooccipital pathway (Figure 1). The existing anatomical feedback projections from higher-level cortical regions to the thalamus and visual cortex support this top-down mechanism [132, $155,159,163,170,171]$. Furthermore, many task-evoked and lesion studies have demonstrated the modulation effects of the fronto-parietal network on the thalamus and visual cortex [165, 188-191]. It seems that in CB subjects, the topdown attention modulation of the occipital activity was strengthened [75, 96, 192-195]. Visual imagery, a complex mental process, can also activate the specific visual areas that are usually recruited by certain visual properties (shape, space, and color), which supports the top-down controlling the visual activities [102-108]. It should be noted that the earlier ERP response cannot exclude the effects of top-down modulation, because top-down attention can also module the early components of ERP, for example, the N1 negativity or even earlier peak $[196,197]$. Furthermore, a ERP study demonstrated that the top-down attention modulation of the occipital activity was significantly strengthened in EB subjects [75]. The following paragraphs state the two popular cognitive processes (visual imagery and attention) that might contribute to the top-down recruitment of the visual cortex.

5.2.1. Visual Imagery. Visual imagery mechanism supports the hypothesis of top-down recruitment of the visual cortex because the mental progress can recruit the visual cortex [102-108]. For example, Kosslyn et al. showed that the visual areas 17 and 18/19 were activated by a stripe imagery task, and rTMS delivered to area 17 did disrupt both visual perception and imagery performance [104]. This study indicates that the early visual areas are involved in at least some forms of visual imagery as well as in visual perception [104]. It is interesting to noted that not only the early visual area, but also the higher-tier ones can specifically respond to the visual imagery task, including the ventral stream for shape imagery $[47,198-200]$, and the dorsal stream for motion and spatial 
imagery [107, 108, 201-203], which highly corresponded with the hierarchy representation of the visual perception. De Volder showed that in both sighted and EB subjects, auditory triggered mental imagery of shape can also activate the ventral occipitotemporal and visual association areas [200].

5.2.2. Attention Controlling. Top-down attention may be the most extensively studied cognitive process that can modulate the activation of the visual cortex [204-208]. It is proposed that visual attention modulates visual processing even at an early stage; it not only modulates the gain on incoming visual information, but also adds a pure top-down signal that increases baseline activity in the visual cortex; moreover, attentional modulation can exert on different aspects of visual perception, such as locations, features, objects, or a combination [208]. Furthermore, not only the visual attention, but also the nonvisual attention can also activate the visual cortex [207, 209-211].

In the $\mathrm{CB}$ subjects, electrophysiological or neuroimaging studies have revealed that the top-down attention modulation was strengthened when they performing tactile/auditory attention-demanding tasks [75, 111, 112, 212-215]. Additionally, the occipital cortical areas were activated in the $\mathrm{CB}$ subjects by attention tasks through nonvisual modalities [60, $96,194,216,217]$. In combination with evidence of attention modulation on visual perception in the SC [218-220], these findings indicate increased top-down attention modulation of occipital activity in the CB.

In summary, the nature of the nonvisual signals to the visual cortex may be either stimulus-driven or top-down, or both. Indeed, effective connectivity analysis offers evidence for the coexistence of both bottom-up and top-down information flows during nonvisual perception [221-223].

\section{Conclusions}

The cross-modal processing of nonvisual signals in the occipital areas in both sighted and EB subjects suggests that the functional organization of the visual cortex is supramodal in nature. The cross-modal plasticity can also account for parts of the findings in the EB subjects. The normally existing thalamo-cortical and corticooccipital pathways provide anatomical evidence for the supramodal nature of the visual cortex. The cross-modal plasticity in the EB might be driven by two neural mechanisms: rewiring and unmasking, although there is lack of in vivo evidence for the former. Further studies with more advanced in vivo imaging techniques should be implemented to clarify this issue. Finally, the nature of the nonvisual signals to the visual cortex may be either stimulus-driven or top-down, or both. Further understanding the issue may help us to design appropriate interventions to improve the adaptive capacity of blind subjects to the external environments.

\section{Acknowledgments}

This study was supported by the National Basic Research Program of China (973 Program, 2011CB707801) and the National Natural Science Foundation of China (81271564).

\section{References}

[1] K. Grill-Spector and R. Malach, "The human visual cortex," Annual Review of Neuroscience, vol. 27, pp. 649-677, 2004.

[2] B. A. Wandell, S. O. Dumoulin, and A. A. Brewer, "Visual field maps in human cortex," Neuron, vol. 56, no. 2, pp. 366-383, 2007.

[3] D. J. Felleman and D. C. Van Essen, "Distributed hierarchical processing in the primate cerebral cortex," Cerebral Cortex, vol. 1, no. 1, pp. 1-47, 1991.

[4] G. Golarai, D. G. Ghahremani, S. Whitfield-Gabrieli et al., "Differential development of high-level visual cortex correlates with category-specific recognition memory," Nature Neuroscience, vol. 10, no. 4, pp. 512-522, 2007.

[5] K. Seymour, C. W. G. Clifford, N. K. Logothetis, and A. Bartels, "Coding and binding of color and form in visual cortex," Cerebral Cortex, vol. 20, no. 8, pp. 1946-1954, 2010.

[6] J. V. Haxby, C. L. Grady, B. Horwitz et al., "Dissociation of object and spatial visual processing pathways in human extrastriate cortex," Proceedings of the National Academy of Sciences of the United States of America, vol. 88, no. 5, pp. 1621-1625, 1991.

[7] M. A. Goodale and A. David Milner, "Separate visual pathways for perception and action," Trends in Neurosciences, vol. 15, no. 1, pp. 20-25, 1992.

[8] C. S. Konen and S. Kastner, "Two hierarchically organized neural systems for object information in human visual cortex," Nature Neuroscience, vol. 11, no. 2, pp. 224-231, 2008.

[9] A. W. McGee, Y. Yang, Q. S. Fischer, N. W. Daw, and S. H. Strittmatter, "Neuroscience: experience-driven plasticity of visual cortex limited by myelin and nogo receptor," Science, vol. 309, no. 5744, pp. 2222-2226, 2005.

[10] E. Putignano, G. Lonetti, L. Cancedda et al., "Developmental downregulation of histone posttranslational modifications regulates visual cortical plasticity," Neuron, vol. 53, no. 5, pp. 747759, 2007.

[11] J. W. Triplett, M. T. Owens, J. Yamada et al., "Retinal input instructs alignment of visual topographic maps," Cell, vol. 139, no. 1, pp. 175-185, 2009.

[12] Y. Li, S. D. Van Hooser, M. Mazurek, L. E. White, and D. Fitzpatrick, "Experience with moving visual stimuli drives the early development of cortical direction selectivity," Nature, vol. 456, no. 7224, pp. 952-956, 2008.

[13] Y. Yazaki-Sugiyama, S. Kang, H. Cteau, T. Fukai, and T. K. Hensch, "Bidirectional plasticity in fast-spiking GABA circuits by visual experience," Nature, vol. 462, no. 7270, pp. 218-221, 2009.

[14] J. Jiang, W. Zhu, F. Shi et al., "Thick visual cortex in the early blind," Journal of Neuroscience, vol. 29, no. 7, pp. 2205-2211, 2009.

[15] H. Park, J. D. Lee, E. Y. Kim et al., "Morphological alterations in the congenital blind based on the analysis of cortical thickness and surface area," NeuroImage, vol. 47, no. 1, pp. 98-106, 2009.

[16] H. Bridge, A. Cowey, N. Ragge, and K. Watkins, "Imaging studies in congenital anophthalmia reveal preservation of brain architecture in "visual" cortex," Brain, vol. 132, no. 12, pp. 34673480, 2009.

[17] W. Qin, Y. Liu, T. Jiang, and C. Yu, “The development of visual areas depends differently on visual experience," PLOS ONE, vol. 8, no. 1, Article ID e53784, 2013.

[18] C. Liu, Y. Liu, W. Li et al., "Increased regional homogeneity of blood oxygen level-dependent signals in occipital cortex of early blind individuals," NeuroReport, vol. 22, no. 4, pp. 190-194, 2011. 
[19] A. G. De Volder, A. Bol, J. Blin et al., "Brain energy metabolism in early blind subjects: neural activity in the visual cortex," Brain Research, vol. 750, no. 1-2, pp. 235-244, 1997.

[20] M. Mishina, M. Senda, M. Kiyosawa et al., "Increased regional cerebral blood flow but normal distribution of GABAA receptor in the visual cortex of subjects with early-onset blindness," NeuroImage, vol. 19, no. 1, pp. 125-131, 2003.

[21] C. Veraart, A. G. De Volder, M. C. Wanet-Defalque, A. Bol, C. Michel, and A. M. Goffinet, "Glucose utilization in human visual cortex is abnormally elevated in blindness of early onset but decreased in blindness of late onset," Brain Research, vol. 510, no. 1, pp. 115-121, 1990.

[22] F. Uhl, P. Franzen, I. Podreka, M. Steiner, and L. Deecke, "Increased regional cerebral blood flow in inferior occipital cortex and cerebellum of early blind humans," Neuroscience Letters, vol. 150, no. 2, pp. 162-164, 1993.

[23] M. Ptito, F. C. G. Schneider, O. B. Paulson, and R. Kupers, "Alterations of the visual pathways in congenital blindness," Experimental Brain Research, vol. 187, no. 1, pp. 41-49, 2008.

[24] U. Noppeney, K. J. Friston, J. Ashburner, R. Frackowiak, and C. J. Price, "Early visual deprivation induces structural plasticity in gray and white matter," Current Biology, vol. 15, no. 13, pp. R488-R490, 2005.

[25] W. Pan, G. Wu, C. Li, F. Lin, J. Sun, and H. Lei, "Progressive atrophy in the optic pathway and visual cortex of early blind Chinese adults: a voxel-based morphometry magnetic resonance imaging study," NeuroImage, vol. 37, no. 1, pp. 212-220, 2007.

[26] J. S. Shimony, H. Burton, A. A. Epstein, D. G. McLaren, S. W. Sun, and A. Z. Snyder, "Diffusion tensor imaging reveals white matter reorganization in early blind humans," Cerebral Cortex, vol. 16, no. 11, pp. 1653-1661, 2006.

[27] N. Shu, J. Li, K. Li, C. Yu, and T. Jiang, "Abnormal diffusion of cerebral white matter in early blindness," Human Brain Mapping, vol. 30, no. 1, pp. 220-227, 2009.

[28] N. Shu, Y. Liu, J. Li, Y. Li, C. Yu, and T. Jiang, "Altered anatomical network in early blindness revealed by diffusion tensor tractography," PLoS ONE, vol. 4, no. 9, Article ID e7228, 2009.

[29] J. Li, Y. Liu, W. Qin et al., "Age of onset of blindness affects brain anatomical networks constructed using diffusion tensor tractography," Cereb Cortex, vol. 23, no. 3, pp. 542-551, 2013.

[30] C. Yu, Y. Liu, J. Li et al., "Altered functional connectivity of primary visual cortex in early blindness," Human Brain Mapping, vol. 29, no. 5, pp. 533-543, 2008.

[31] Y. Liu, C. Yu, M. Liang et al., "Whole brain functional connectivity in the early blind," Brain, vol. 130, no. 8, pp. 2085-2096, 2007.

[32] D. Bavelier and H. J. Neville, "Cross-modal plasticity: where and how?" Nature Reviews Neuroscience, vol. 3, no. 6, pp. 443-452, 2002.

[33] K. Fiehler and F. Rösler, "Plasticity of multisensory dorsal stream functions: evidence from congenitally blind and sighted adults," Restorative Neurology and Neuroscience, vol. 28, no. 2, pp. 193-205, 2010.

[34] N. Sadato, "Chapter 11 Cross-modal plasticity in the blind revealed by functional neuroimaging," Supplements to Clinical Neurophysiology, vol. 59, pp. 75-79, 2006.

[35] K. Sathian and R. Stilla, "Cross-modal plasticity of tactile perception in blindness," Restorative Neurology and Neuroscience, vol. 28 , no. 2, pp. 271-281, 2010.
[36] O. Collignon, P. Voss, M. Lassonde, and F. Lepore, "Crossmodal plasticity for the spatial processing of sounds in visually deprived subjects," Experimental Brain Research, vol. 192, no. 3, pp. 343-358, 2009.

[37] E. Ricciardi, N. Vanello, L. Sani et al., "The effect of visual experience on the development of functional architecture in hMT+," Cerebral Cortex, vol. 17, no. 12, pp. 2933-2939, 2007.

[38] P. Pietrini, M. L. Furey, E. Ricciardi et al., "Beyond sensory images: object-based representation in the human ventral pathway," Proceedings of the National Academy of Sciences of the United States of America, vol. 101, no. 15, pp. 5658-5663, 2004.

[39] K. Sathian, A. Zangaladze, J. M. Hoffman, and S. T. Grafton, "Feeling with the mind's eye," NeuroReport, vol. 8, no. 18, pp. 3877-3881, 1997.

[40] A. Zangaladze, C. M. Epstein, S. T. Grafton, and K. Sathian, "Involvement of visual cortex in tactile discrimination orientation," Nature, vol. 401, no. 6753, pp. 587-590, 1999.

[41] E. Ricciardi, D. Basso, L. Sani et al., "Functional inhibition of the human middle temporal cortex affects non-visual motion perception: a repetitive transcranial magnetic stimulation study during tactile speed discrimination," Experimental Biology and Medicine, vol. 236, no. 2, pp. 138-144, 2011.

[42] M. Ptito, I. Matteau, A. Zhi Wang, O. B. Paulson, H. R. Siebner, and R. Kupers, "Crossmodal recruitment of the ventral visual stream in congenital blindness," Neural Plasticity, vol. 2012, Article ID 304045, 9 pages, 2012.

[43] T. W. James, G. K. Humphrey, J. S. Gati, R. S. Menon, and M. A. Goodale, "Differential effects of viewpoint on object-driven activation in dorsal and ventral streams," Neuron, vol. 35, no. 4, pp. 793-801, 2002.

[44] T. W. James, G. K. Humphrey, J. S. Gati, P. Servos, R. S. Menon, and M. A. Goodale, "Haptic study of three-dimensional objects activates extrastriate visual areas," Neuropsychologia, vol. 40, no. 10, pp. 1706-1714, 2002.

[45] A. Amedi, G. Jacobson, T. Hendler, R. Malach, and E. Zohary, "Convergence of visual and tactile shape processing in the human lateral occipital complex zohary," Cerebral Cortex, vol. 12, no. 11, pp. 1202-1212, 2002.

[46] A. Amedi, R. Malach, T. Hendler, S. Peled, and E. Zohary, "Visuo-haptic object-related activation in the ventral visual pathway," Nature Neuroscience, vol. 4, no. 3, pp. 324-330, 2001.

[47] M. Zhang, V. D. Weisser, R. Stilla, S. C. Prather, and K. Sathian, "Multisensory cortical processing of object shape and its relation to mental imagery," Cognitive, Affective and Behavioral Neuroscience, vol. 4, no. 2, pp. 251-259, 2004.

[48] M. R. Stoesz, M. Zhang, V. D. Weisser, S. C. Prather, H. Mao, and K. Sathian, "Neural networks active during tactile form perception: common and differential activity during macrospatial and microspatial tasks," International Journal of Psychophysiology, vol. 50, no. 1-2, pp. 41-49, 2003.

[49] S. C. Prather, J. R. Votaw, and K. Sathian, “Task-specific recruitment of dorsal and ventral visual areas during tactile perception," Neuropsychologia, vol. 42, no. 8, pp. 1079-1087, 2004.

[50] I. Matteau, R. Kupers, E. Ricciardi, P. Pietrini, and M. Ptito, "Beyond visual, aural and haptic movement perception: hMT+ is activated by electrotactile motion stimulation of the tongue in sighted and in congenitally blind individuals," Brain Research Bulletin, vol. 82, no. 5-6, pp. 264-270, 2010.

[51] F. Morrell, "Visual system's view of acoustic space," Nature, vol. 238, no. 5358, pp. 44-46, 1972. 
[52] C. Poirier, O. Collignon, A. G. DeVolder et al., "Specific activation of the V5 brain area by auditory motion processing: an fMRI study," Cognitive Brain Research, vol. 25, no. 3, pp. 650658, 2005.

[53] U. Zimmer, J. Lewald, M. Erb, W. Grodd, and H. Karnath, "Is there a role of visual cortex in spatial hearing?" European Journal of Neuroscience, vol. 20, no. 11, pp. 3148-3156, 2004.

[54] C. Poirier, O. Collignon, C. Scheiber et al., "Auditory motion perception activates visual motion areas in early blind subjects," NeuroImage, vol. 31, no. 1, pp. 279-285, 2006.

[55] E. Ricciardi, "Brain response to visual, tactile and auditory flow in sighted and blind individuals supports a supramodal functional organization in hMT+ complex," Neuroimage, vol. 31, no. 1, supplement, p. 512, 2006.

[56] J. Lewald, I. G. Meister, J. Weidemann, and R. Töpper, "Involvement of the superior temporal cortex and the occipital cortex in spatial hearing: evidence from repetitive transcranial magnetic stimulation," Journal of Cognitive Neuroscience, vol. 16, no. 5, pp. 828-838, 2004.

[57] O. Collignon, M. Davare, E. Olivier, and A. G. De Volder, "Reorganisation of the right occipito-parietal stream for auditory spatial processing in early blind humans. a transcranial magnetic stimulation study," Brain Topography, vol. 21, no. 3-4, pp. 232-240, 2009.

[58] O. Collignon, M. Davare, A. G. De Volder, C. Poirier, E. Olivier, and C. Veraart, "Time-course of posterior parietal and occipital cortex contribution to sound localization," Journal of Cognitive Neuroscience, vol. 20, no. 8, pp. 1454-1463, 2008.

[59] E. Ricciardi, D. Bonino, L. Sani et al., "Do we really need vision? How blind people "see" the actions of others," Journal of Neuroscience, vol. 29, no. 31, pp. 9719-9724, 2009.

[60] H. Burton, R. J. Sinclair, and D. G. McLaren, "Cortical activity to vibrotactile stimulation: an fMRI study in blind and sighted individuals," Human Brain Mapping, vol. 23, no. 4, pp. 210-228, 2004.

[61] M. Ptito, I. Matteau, A. Gjedde, and R. Kupers, "Recruitment of the middle temporal area by tactile motion in congenital blindness," NeuroReport, vol. 20, no. 6, pp. 543-547, 2009.

[62] R. Kupers, D. R. Chebat, K. H. Madsen, O. B. Paulson, and M. Ptito, "Neural correlates of virtual route recognition in congenital blindness," Proceedings of the National Academy of Sciences of the United States of America, vol. 107, no. 28, pp. 12716-12721, 2010.

[63] M. Ptito, S. M. Moesgaard, A. Gjedde, and R. Kupers, "Crossmodal plasticity revealed by electrotactile stimulation of the tongue in the congenitally blind," Brain, vol. 128, no. 3, pp. 606614, 2005.

[64] R. Kupers, A. Fumal, A. M. De Noordhout, A. Gjedde, J. Schoenen, and M. Ptito, "Transcranial magnetic stimulation of the visual cortex induces somatotopically organized qualia in blind subjects," Proceedings of the National Academy of Sciences of the United States of America, vol. 103, no. 35, pp. 13256-13260, 2006.

[65] P. Arno, A. G. De Volder, A. Vanlierde et al., "Occipital activation by pattern recognition in the early blind using auditory substitution for vision," NeuroImage, vol. 13, no. 4, pp. 632-645, 2001.

[66] L. A. Renier, I. Anurova, A. G. De Volder, S. Carlson, J. VanMeter, and J. P. Rauschecker, "Preserved functional specialization for spatial processing in the middle occipital gyrus of the early blind," Neuron, vol. 68, no. 1, pp. 138-148, 2010.
[67] R. Weeks, B. Horwitz, A. Aziz-Sultan et al., "A positron emission tomographic study of auditory localization in the congenitally blind," Journal of Neuroscience, vol. 20, no. 7, pp. 2664-2672, 2000.

[68] G. Dormal, F. Lepore, and O. Collignon, "Plasticity of the dorsal "spatial" stream in visually deprived individuals," Neural Plasticity, vol. 2012, Article ID 687659, 12 pages, 2012.

[69] O. Collignon, G. Vandewalle, P. Voss et al., "Functional specialization for auditory-spatial processing in the occipital cortex of congenitally blind humans," Proceedings of the National Academy of Sciences of the United States of America, vol. 108, no. 11, pp. 4435-4440, 2011.

[70] T. Wolbers, P. Zahorik, and N. A. Giudice, "Decoding the direction of auditory motion in blind humans," NeuroImage, vol. 56, no. 2, pp. 681-687, 2011.

[71] M. Bedny, T. Konkle, K. Pelphrey, R. Saxe, and A. PascualLeone, "Sensitive period for a multimodal response in human visual motion area MT/MST," Current Biology, vol. 20, no. 21, pp. 1900-1906, 2010.

[72] A. Amedi, W. M. Stern, J. A. Camprodon et al., "Shape conveyed by visual-to-auditory sensory substitution activates the lateral occipital complex," Nature Neuroscience, vol. 10, no. 6, pp. 687689, 2007.

[73] J. Kim and R. J. Zatorre, "Tactile-auditory shape learning engages the lateral occipital complex," Journal of Neuroscience, vol. 31, no. 21, pp. 7848-7856, 2011.

[74] E. Striem-Amit, O. Dakwar, L. Reich, and A. Amedi, “The largescale organization of "visual" streams emerges without visual experience," Cereb Cortex, vol. 22, no. 7, pp. 1698-1709, 2012.

[75] B. Röder, W. Teder-Sälejärvi, A. Sterr, F. Rösler, S. A. Hillyard, and H. J. Neville, "Improved auditory spatial tuning in blind humans," Nature, vol. 400, no. 6740, pp. 162-166, 1999.

[76] C. Leclerc, S. J. Segalowitz, J. Desjardins, M. Lassonde, and F. Lepore, "EEG coherence in early-blind humans during sound localization," Neuroscience Letters, vol. 376, no. 3, pp. 154-159, 2005.

[77] C. Leclerc, D. Saint-Amour, M. E. Lavoie, M. Lassonde, and F. Lepore, "Brain functional reorganization in early blind humans revealed by auditory event-related potentials," NeuroReport, vol. 11, no. 3, pp. 545-550, 2000.

[78] O. Collignon, M. Lassonde, F. Lepore, D. Bastien, and C. Veraart, "Functional cerebral reorganization for auditory spatial processing and auditory substitution of vision in early blind subjects," Cerebral Cortex, vol. 17, no. 2, pp. 457-465, 2007.

[79] L. B. Merabet, L. Battelli, S. Obretenova, S. Maguire, P. Meijer, and A. Pascual-Leone, "Functional recruitment of visual cortex for sound encoded object identification in the blind," NeuroReport, vol. 20, no. 2, pp. 132-138, 2009.

[80] R. Kupers, M. Beaulieu-Lefebvre, F. C. Schneider et al., "Neural correlates of olfactory processing in congenital blindness," Neuropsychologia, vol. 49, no. 7, pp. 2037-2044, 2011.

[81] M. Beaulieu-Lefebvre, F. C. Schneider, R. Kupers, and M. Ptito, "Odor perception and odor awareness in congenital blindness," Brain Research Bulletin, vol. 84, no. 3, pp. 206-209, 2011.

[82] I. Cuevas, P. Plaza, P. Rombaux, A. G. De Volder, and L. Renier, "Odour discrimination and identification are improved in early blindness," Neuropsychologia, vol. 47, no. 14, pp. 3079-3083, 2009.

[83] N. Sadato, A. Pascual-Leone, J. Grafman et al., "Activation of the primary visual cortex by Braille reading in blind subjects," Nature, vol. 380, no. 6574, pp. 526-528, 1996. 
[84] L. G. Cohen, R. A. Weeks, N. Sadato, P. Celnik, K. Ishii, and M. Hallett, "Period of susceptibility for cross-modal plasticity in the blind," Annals of Neurology, vol. 45, no. 4, pp. 451-460, 1999.

[85] N. Sadato, T. Okada, M. Honda, and Y. Yonekura, "Critical period for cross-modal plasticity in blind humans: a functional MRI study," NeuroImage, vol. 16, no. 2, pp. 389-400, 2002.

[86] H. Burton, A. Z. Snyder, T. E. Conturo, E. Akbudak, J. M. Ollinger, and M. E. Raichle, "Adaptive changes in early and late blind: a fMRI study of Braille reading," Journal of Neurophysiology, vol. 87, no. 1, pp. 589-607, 2002.

[87] H. Burton, A. Z. Snyder, J. B. Diamond, and M. E. Raichle, "Adaptive changes in early and late blind: a fMRI study of verb generation to heard nouns," Journal of Neurophysiology, vol. 88, no. 6, pp. 3359-3371, 2002.

[88] H. Burton, J. B. Diamond, and K. B. McDermott, "Dissociating cortical regions activated by semantic and phonological tasks: a fMRI study in blind and sighted people," Journal of Neurophysiology, vol. 90, no. 3, pp. 1965-1982, 2003.

[89] B. Röder, O. Stock, S. Bien, H. Neville, and F. Rösler, "Speech processing activates visual cortex in congenitally blind humans," European Journal of Neuroscience, vol. 16, no. 5, pp. 930-936, 2002.

[90] L. Reich, M. Szwed, L. Cohen, and A. Amedi, "A ventral visual stream reading center independent of visual experience," Current Biology, vol. 21, no. 5, pp. 363-368, 2011.

[91] M. Bedny, A. Pascual-Leone, D. Dodell-Feder, E. Fedorenko, and R. Saxe, "Language processing in the occipital cortex of congenitally blind adults," Proceedings of the National Academy of Sciences of the United States of America, vol. 108, no. 11, pp. 4429-4434, 2011.

[92] L. G. Cohen, P. Celnik, A. Pascual-Leone et al., "Functional relevance of cross-modal plasticity in blind humans," Nature, vol. 389, no. 6647, pp. 180-183, 1997.

[93] A. Amedi, A. Floel, S. Knecht, E. Zohary, and L. G. Cohen, "Transcranial magnetic stimulation of the occipital pole interferes with verbal processing in blind subjects," Nature Neuroscience, vol. 7, no. 11, pp. 1266-1270, 2004.

[94] R. Hamilton, J. P. Keenan, M. Catala, and A. Pascual-Leone, "Alexia for Braille following bilateral occipital stroke in an early blind woman," NeuroReport, vol. 11, no. 2, pp. 237-240, 2000.

[95] K. Maeda, H. Yasuda, M. Haneda, and A. Kashiwagi, "Braille alexia during visual hallucination in a blind man with selective calcarine atrophy," Psychiatry and Clinical Neurosciences, vol. 57, no. 2, pp. 227-229, 2003.

[96] A. A. Stevens, M. Snodgrass, D. Schwartz, and K. Weaver, "Preparatory activity in occipital cortex in early blind humans predicts auditory perceptual performance," Journal of Neuroscience, vol. 27, no. 40, pp. 10734-10741, 2007.

[97] F. Gougoux, R. J. Zatorre, M. Lassonde, P. Voss, and F. Lepore, "A functional neuroimaging study of sound localization: visual cortex activity predicts performance in early-blind individuals," PLoS Biology, vol. 3, no. 2, article e27, 2005.

[98] H. Burton, R. J. Sinclair, and A. Agato, "Recognition memory for Braille or spoken words: an fMRI study in early blind," Brain Research, vol. 1438, pp. 22-34, 2012.

[99] H. J. Park, "Activation of the occipital cortex and deactivation of the default mode network during working memory in the early blind," Journal of the International Neuropsychological Society, vol. 17, pp. 407-422, 2011.
[100] D. Bonino, E. Ricciardi, L. Sani et al., "Tactile spatial working memory activates the dorsal extrastriate cortical pathway in congenitally blind individuals," Archives Italiennes de Biologie, vol. 146, no. 3-4, pp. 133-146, 2008.

[101] A. Amedi, N. Raz, P. Pianka, R. Malach, and E. Zohary, "Early "visual" cortex activation correlates with superior verbal memory performance in the blind," Nature Neuroscience, vol. 6, no. 7, pp. 758-766, 2003.

[102] K. Sathian and A. Zangaladze, "Feeling with the mind's eye: the role of visual imagery in tactile perception," Optometry and Vision Science, vol. 78, no. 5, pp. 276-281, 2001.

[103] S. M. Kosslyn, W. L. Thompson, I. J. Kim, and N. M. Alpert, "Topographical representations of mental images in primary visual cortex," Nature, vol. 378, no. 6556, pp. 496-498, 1995.

[104] S. M. Kosslyn, A. Pascual-Leone, O. Felician et al., "The role of area 17 in visual imagery: convergent evidence from PET and rTMS," Science, vol. 284, no. 5411, pp. 167-170, 1999.

[105] S. Lee, D. J. Kravitz, and C. I. Baker, "Disentangling visual imagery and perception of real-world objects," NeuroImage, vol. 59, no. 4, pp. 4064-4073, 2012.

[106] Z. Cattaneo, S. Bona, and J. Silvanto, "Cross-adaptation combined with TMS reveals a functional overlap between vision and imagery in the early visual cortex," NeuroImage, vol. 59, no. 3, pp. 3015-3020, 2012.

[107] R. Seurinck, F. P. de Lange, E. Achten, and G. Vingerhoets, "Mental rotation meets the motion aftereffect: the role of hV5/MT+ in visual mental imagery," Journal of Cognitive Neuroscience, vol. 23, no. 6, pp. 1395-1404, 2011.

[108] A. Kaas, S. Weigelt, A. Roebroeck, A. Kohler, and L. Muckli, "Imagery of a moving object: the role of occipital cortex and human MT/V5+," NeuroImage, vol. 49, no. 1, pp. 794-804, 2010.

[109] B. Z. Mahon, J. Schwarzbach, and A. Caramazza, "The representation of tools in left parietal cortex is independent of visual experience," Psychological Science, vol. 21, no. 6, pp. 764-771, 2010.

[110] B. Z. Mahon, S. Anzellotti, J. Schwarzbach, M. Zampini, and A. Caramazza, "Category-specific organization in the human brain does not require visual experience," Neuron, vol. 63, no. 3, pp. 397-405, 2009.

[111] O. Collignon and A. G. De Voider, "Further evidence that congenitally blind participants react faster to auditory and tactile spatial targets," Canadian Journal of Experimental Psychology, vol. 63, no. 4, pp. 287-293, 2009.

[112] O. Collignon, L. Renier, R. Bruyer, D. Tranduy, and C. Veraart, "Improved selective and divided spatial attention in early blind subjects," Brain Research, vol. 1075, no. 1, pp. 175-182, 2006.

[113] N. Lessard, M. Paré, F. Lepore, and M. Lassonde, "Early-blind human subjects localize sound sources better than sighted subjects," Nature, vol. 395, no. 6699, pp. 278-280, 1998.

[114] D. Goldreich and I. M. Kanics, "Tactile acuity is enhanced in blindness," Journal of Neuroscience, vol. 23, no. 8, pp. 3439-3445, 2003.

[115] R. W. Van Boven, R. H. Hamilton, T. Kauffman, J. P. Keenan, and A. Pascual-Leone, "Tactile spatial resolution in blind Braille readers," Neurology, vol. 54, no. 12, pp. 2230-2236, 2000.

[116] L. Sani, E. Ricciardi, C. Gentili, N. Vanello, J. V. Haxby, and P. Pietrini, "Effects of visual experience on the human MT+ functional connectivity networks: an fMRI study of motion perception in sighted and congenitally blind individuals," Frontiers in Systems Neuroscience, vol. 4, article 159, 2010. 
[117] J. P. Rauschecker, B. Tian, M. Korte, and U. Egert, "Crossmodal changes in the somatosensory vibrissa/barrel system of visually deprived animals," Proceedings of the National Academy of Sciences of the United States of America, vol. 89, no. 11, pp. 50635067, 1992.

[118] J. P. Rauschecker and M. Korte, "Auditory compensation for early blindness in cat cerebral cortex," Journal of Neuroscience, vol. 13, no. 10, pp. 4538-4548, 1993.

[119] J. P. Rauschecker, "Compensatory plasticity and sensory substitution in the cerebral cortex," Trends in Neurosciences, vol. 18, no. 1, pp. 36-43, 1995.

[120] A. Morel, M. Magnin, and D. Jeanmonod, "Multiarchitectonic and stereotactic atlas of the human thalamus," Journal of Comparative Neurology, vol. 387, no. 4, pp. 588-630, 1997.

[121] G. Percheron, C. François, B. Talbi, J. Yelnik, and G. Fénelon, "The primate motor thalamus," Brain Research Reviews, vol. 22, no. 2, pp. 93-181, 1996.

[122] A. M. Sillito, J. Cudeiro, and H. E. Jones, "Always returning: feedback and sensory processing in visual cortex and thalamus," Trends in Neurosciences, vol. 29, no. 6, pp. 307-316, 2006.

[123] J. A. Winer, M. L. Chernock, D. T. Larue, and S. W. Cheung, "Descending projections to the inferior colliculus from the posterior thalamus and the auditory cortex in rat, cat, and monkey," Hearing Research, vol. 168, no. 1-2, pp. 181-195, 2002.

[124] L. Li and F. F. Ebner, "Cortical modulation of spatial and angular tuning maps in the rat thalamus," Journal of Neuroscience, vol. 27, no. 1, pp. 167-179, 2007.

[125] Y. Lam and S. M. Sherman, "Functional organization of the somatosensory cortical layer 6 feedback to the thalamus," Cerebral Cortex, vol. 20, no. 1, pp. 13-24, 2010.

[126] M. Iacoboni, "Adjusting reaches: feedback in the posterior parietal cortex," Nature Neuroscience, vol. 2, no. 6, pp. 492-494, 1999.

[127] M. A. Sommer and R. H. Wurtz, "What the brain stem tells the frontal cortex-I. Oculomotor signals sent from superior colliculus to frontal eye field via mediodorsal thalamus," Journal of Neurophysiology, vol. 91, no. 3, pp. 1381-1402, 2004.

[128] L. M. Romanski, M. Giguere, J. F. Bates, and P. S. GoldmanRakic, "Topographic organization of medial pulvinar connections with the prefrontal cortex in the rhesus monkey," Journal of Comparative Neurology, vol. 379, no. 3, pp. 313-332, 1997.

[129] E. Salzmann, "Attention and memory trials during neuronal recording from the primate pulvinar and posterior parietal cortex (area PG)," Behavioural Brain Research, vol. 67, no. 2, pp. 241-253, 1995.

[130] C.-S. Lin and J. H. Kaas, "Projections from the medial nucleus of the inferior pulvinar complex to the middle temporal area of the visual cortex," Neuroscience, vol. 5, no. 12, pp. 2219-2228, 1980.

[131] D. A. Simpson, "The projection of the pulvinar to the temporal lobe," Journal of Anatomy, vol. 86, no. 1, pp. 20-28, 1952.

[132] S. Shipp, "The functional logic of cortico-pulvinar connections," Philosophical Transactions of the Royal Society B, vol. 358, no. 1438, pp. 1605-1624, 2003.

[133] N. Chabot, V. Charbonneau, M. Laramée, R. Tremblay, D. Boire, and G. Bronchti, "Subcortical auditory input to the primary visual cortex in anophthalmic mice," Neuroscience Letters, vol. 433, no. 2, pp. 129-134, 2008.

[134] R. Izraeli, G. Koay, M. Lamish et al., "Cross-modal neuroplasticity in neonatally enucleated hamsters: structure, electrophysiology and behaviour," European Journal of Neuroscience, vol. 15, no. 4, pp. 693-712, 2002.
[135] N. Doron and Z. Wollberg, "Cross-modal neuroplasticity in the blind mole rat Spalax Ehrenbergi: a WGA-HRP tracing study," NeuroReport, vol. 5, no. 18, pp. 2697-2701, 1994.

[136] M. Piché, N. Chabot, G. Bronchti, D. Miceli, F. Lepore, and J.-P. Guillemot, "Auditory responses in the visual cortex of neonatally enucleated rats," Neuroscience, vol. 145, no. 3, pp. 1144-1156, 2007.

[137] M. Piché, S. Robert, D. Miceli, and G. Bronchti, “Environmental enrichment enhances auditory takeover of the occipital cortex in anophthalmic mice," European Journal of Neuroscience, vol. 20, no. 12, pp. 3463-3472, 2004.

[138] G. Bronchti, P. Heil, R. Sadka, A. Hess, H. Scheich, and Z. Wollberg, "Auditory activation of "visual" cortical areas in the blind mole rat (Spalax ehrenbergi)," European Journal of Neuroscience, vol. 16, no. 2, pp. 311-329, 2002.

[139] N. Chabot, S. Robert, R. Tremblay, D. Miceli, D. Boire, and G. Bronchti, "Audition differently activates the visual system in neonatally enucleated mice compared with anophthalmic mutants," European Journal of Neuroscience, vol. 26, no. 8, pp. 2334-2348, 2007.

[140] S. J. Karlen, D. M. Kahn, and L. Krubitzer, "Early blindness results in abnormal corticocortical and thalamocortical connections," Neuroscience, vol. 142, no. 3, pp. 843-858, 2006.

[141] G. Rehkamper, R. Necker, and E. Nevo, "Functional anatomy of the thalamus in the blind mole rat Spalax ehrenbergi: an architectonic and electrophysiologically controlled tracing study," Journal of Comparative Neurology, vol. 347, no. 4, pp. 570-584, 1994.

[142] G. Bronchti, R. Rado, J. Terkel, and Z. Wollberg, "Retinal projections in the blind mole rat: a WGA-HRP tracing study of a natural degenertion," Developmental Brain Research, vol. 58, no. 2, pp. 159-170, 1991.

[143] Y. B. Saalmann, M. A. Pinsk, L. Wang, X. Li, and S. Kastner, "The pulvinar regulates information transmission between cortical areas based on attention demands," Science, vol. 337, no. 6095, pp. 753-756, 2012.

[144] J. H. Kaas and D. C. Lyon, "Pulvinar contributions to the dorsal and ventral streams of visual processing in primates," Brain Research Reviews, vol. 55, no. 2, pp. 285-296, 2007.

[145] C. Casanova, L. Merabet, A. Desautels, and K. Minville, "Higher-order motion processing in the pulvinar," Progress in Brain Research, vol. 134, pp. 71-82, 2001.

[146] K. L. Grieve, C. Acuña, and J. Cudeiro, "The primate pulvinar nuclei: vision and action," Trends in Neurosciences, vol. 23, no. 1, pp. 35-39, 2000.

[147] A. Gaglianese, M. Costagli, G. Bernardi, E. Ricciardi, and P. Pietrini, "Evidence of a direct influence between the thalamus and hMT+ independent of V1 in the human brain as measured by fMRI," NeuroImage, vol. 60, no. 2, pp. 1440-1447, 2012.

[148] M. A. Schoenfeld, H.-J. Heinze, and M. G. Woldorff, "Unmasking motion-processing activity in human brain area V5/MT+ mediated by pathways that bypass primary visual cortex," NeuroImage, vol. 17, no. 2, pp. 769-779, 2002.

[149] L. G. Ungerleider, R. Desimone, T. W. Galkin, and M. Mishkin, "Subcortical projections of area MT in the Macaque," Journal of Comparative Neurology, vol. 223, no. 3, pp. 368-386, 1984.

[150] A. Lysakowski, G. P. Standage, and L. A. Benevento, "An investigation of collateral projections of the dorsal lateral geniculate nucleus and other subcortical structures to cortical areas V1 and V4 in the macaque monkey: a double label retrograde tracer study," Experimental Brain Research, vol. 69, no. 3, pp. 651-661, 1988. 
[151] M. C. Schmid, S. W. Mrowka, J. Turchi et al., "Blindsight depends on the lateral geniculate nucleus," Nature, vol. 466, no. 7304, pp. 373-377, 2010.

[152] A. S. Bock, C. D. Kroenke, E. N. Taber, and J. F. Olavarria, "Retinal input influences the size and corticocortical connectivity of visual cortex during postnatal development in the ferret," Journal of Comparative Neurology, vol. 520, no. 5, pp. 914-932, 2012.

[153] A. Falchier, S. Clavagnier, P. Barone, and H. Kennedy, "Anatomical evidence of multimodal integration in primate striate cortex," Journal of Neuroscience, vol. 22, no. 13, pp. 5749-5759, 2002.

[154] E. Budinger, P. Heil, A. Hess, and H. Scheich, "Multisensory processing via early cortical stages: connections of the primary auditory cortical field with other sensory systems," Neuroscience, vol. 143, no. 4, pp. 1065-1083, 2006.

[155] H. Ruth Clemo, G. K. Sharma, B. L. Allman, and M. Alex Meredith, "Auditory projections to extrastriate visual cortex: connectional basis for multisensory processing in 'unimodal' visual neurons," Experimental Brain Research, vol. 191, no. 1, pp. 37-47, 2008.

[156] A. Falchier, C. E. Schroeder, T. A. Hackett et al., "Projection from visual areas V2 and prostriata to caudal auditory cortex in the monkey," Cerebral Cortex, vol. 20, no. 7, pp. 1529-1538, 2010.

[157] S. Clavagnier, A. Falchier, and H. Kennedy, "Long-distance feedback projections to area V1: implications for multisensory integration, spatial awareness, and visual consciousness," Cognitive, Affective and Behavioral Neuroscience, vol. 4, no. 2, pp. 117-126, 2004.

[158] A. L. Beer, T. Plank, and M. W. Greenlee, "Diffusion tensor imaging shows white matter tracts between human auditory and visual cortex," Experimental Brain Research, vol. 213, no. 23, pp. 299-308, 2011.

[159] J. Driver and T. Noesselt, "Multisensory interplay reveals crossmodal influences on "sensory-specific" brain regions, neural responses, and judgments," Neuron, vol. 57, no. 1, pp. 11-23, 2008.

[160] J. W. Lewis and D. C. Van Essen, "Corticocortical connections of visual, sensorimotor, and multimodal processing areas in the parietal lobe of the macaque monkey," Journal of Comparative Neurology, vol. 428, no. 1, pp. 112-137, 2000.

[161] M. S. Beauchamp, S. Pasalar, and T. Ro, "Neural substrates of reliability-weighted visual-tactile multisensory integration," Frontiers in Systems Neuroscience, vol. 4, article 25, 2010.

[162] G. A. Calvert, P. C. Hansen, S. D. Iversen, and M. J. Brammer, "Detection of audio-visual integration sites in humans by application of electrophysiological criteria to the BOLD effect," NeuroImage, vol. 14, no. 2, pp. 427-438, 2001.

[163] J. F. Smiley and A. Falchier, "Multisensory connections of monkey auditory cerebral cortex," Hearing Research, vol. 258, no. 1-2, pp. 37-46, 2009.

[164] T. Noesselt, J. W. Rieger, M. A. Schoenfeld et al., "Audiovisual temporal correspondence modulates human multisensory superior temporal sulcus plus primary sensory cortices," Journal of Neuroscience, vol. 27, no. 42, pp. 11431-11441, 2007.

[165] S. Werner and U. Noppeney, "Distinct functional contributions of primary sensory and association areas to audiovisual integration in object categorization," Journal of Neuroscience, vol. 30, no. 7, pp. 2662-2675, 2010.

[166] T. Sugihara, M. D. Diltz, B. B. Averbeck, and L. M. Romanski, "Integration of auditory and visual communication information in the primate ventrolateral prefrontal cortex," Journal of Neuroscience, vol. 26, no. 43, pp. 11138-11147, 2006.

[167] L. M. Romanski, "Representation and integration of auditory and visual stimuli in the primate ventral lateral prefrontal cortex," Cerebral Cortex, vol. 17, supplement, pp. i61-69, 2007.

[168] K. S. Rockland and H. Ojima, "Multisensory convergence in calcarine visual areas in macaque monkey," International Journal of Psychophysiology, vol. 50, no. 1-2, pp. 19-26, 2003.

[169] M. E. Laramée, T. Kurotani, K. S. Rockland, G. Bronchti, and D. Boire, "Indirect pathway between the primary auditory and visual cortices through layer $\mathrm{V}$ pyramidal neurons in V2L in mouse and the effects of bilateral enucleation," European Journal of Neuroscience, vol. 34, no. 1, pp. 65-78, 2011.

[170] J. D. Schmahmann and D. N. Pandya, "The complex history of the fronto-occipital fasciculus," Journal of the History of the Neurosciences, vol. 16, no. 4, pp. 362-377, 2007.

[171] J. D. Schmahmann, D. N. Pandya, R. Wang et al., "Association fibre pathways of the brain: parallel observations from diffusion spectrum imaging and autoradiography," Brain, vol. 130, no. 3, pp. 630-653, 2007.

[172] H. E. M. Den Ouden, K. J. Friston, N. D. Daw, A. R. McIntosh, and K. E. Stephan, "A dual role for prediction error in associative learning," Cerebral Cortex, vol. 19, no. 5, pp. 1175-1185, 2009.

[173] M. A. Eckert, N. V. Kamdar, C. E. Chang, C. F. Beckmann, M. D. Greicius, and V. Menon, "A cross-modal system linking primary auditory and visual cortices: evidence from intrinsic fMRI connectivity analysis," Human Brain Mapping, vol. 29, no. 7, pp. 848-857, 2008.

[174] C. Klinge, F. Eippert, B. Röder, and C. Büchel, "Corticocortical connections mediate primary visual cortex responses to auditory stimulation in the blind," Journal of Neuroscience, vol. 30, no. 38, pp. 12798-12805, 2010.

[175] G. F. Wittenberg, K. J. Werhahn, E. M. Wassermann, P. Herscovitch, and L. G. Cohen, "Functional connectivity between somatosensory and visual cortex in early blind humans," European Journal of Neuroscience, vol. 20, no. 7, pp. 1923-1927, 2004.

[176] M. Ptito, A. Fumal, A. M. De Noordhout, J. Schoenen, A. Gjedde, and R. Kupers, "TMS of the occipital cortex induces tactile sensations in the fingers of blind Braille readers," Experimental Brain Research, vol. 184, no. 2, pp. 193-200, 2008.

[177] L. A. de la Mothe, S. Blumell, Y. Kajikawa, and T. A. Hackett, "Thalamic connections of auditory cortex in marmoset monkeys: lateral belt and parabelt regions," Anatomical Record, vol. 295, no. 5, pp. 822-836, 2012.

[178] M. Ptito, J.-F. Giguère, D. Boire, D. O. Frost, and C. Casanova, "When the auditory cortex turns visual," Progress in Brain Research, vol. 134, pp. 447-458, 2001.

[179] M. Ptito and R. Kupers, "Cross-modal plasticity in early blindness," Journal of Integrative Neuroscience, vol. 4, no. 4, pp. 479-488, 2005.

[180] E. Macaluso, C. D. Frith, and J. Driver, "Modulation of human visual cortex by crossmodal spatial attention," Science, vol. 289, no. 5482, pp. 1206-1208, 2000.

[181] S. Facchini and S. M. Aglioti, "Short term light deprivation increases tactile spatial acuity in humans," Neurology, vol. 60, no. 12, pp. 1998-1999, 2003.

[182] B. Boroojerdi, K. O. Bushara, B. Corwell et al., "Enhanced excitability of the human visual cortex induced by short-term light deprivation," Cerebral Cortex, vol. 10, no. 5, pp. 529-534, 2000 . 
[183] L. B. Merabet, R. Hamilton, G. Schlaug et al., "Rapid and reversible recruitment of early visual cortex for touch," PLoS ONE, vol. 3, no. 8, Article ID e3046, 2008.

[184] A. Pascual-Leone and R. Hamilton, "The metamodal organization of the brain," Progress in Brain Research, vol. 134, pp. 427445, 2001.

[185] J. Lewald, "More accurate sound localization induced by shortterm light deprivation," Neuropsychologia, vol. 45, no. 6, pp. 1215-1222, 2007.

[186] A. Amedi, N. Raz, H. Azulay, R. Malach, and E. Zohary, "Cortical activity during tactile exploration of objects in blind and sighted humans," Restorative Neurology and Neuroscience, vol. 28, no. 2, pp. 143-156, 2010.

[187] J. N. Lucan, J. J. Foxe, M. Gomez-Ramirez, K. Sathian, and S. Molholm, "Tactile shape discrimination recruits human lateral occipital complex during early perceptual processing," Human Brain Mapping, vol. 31, no. 11, pp. 1813-1821, 2010.

[188] A. F. Rossi, N. P. Bichot, R. Desimone, and L. G. Ungerleider, "Top-down attentional deficits in Macaques with lesions of lateral prefrontal cortex," Journal of Neuroscience, vol. 27, no. 42, pp. 11306-11314, 2007.

[189] S. R. Friedman-Hill, L. C. Robertson, R. Desimone, and L. G. Ungerleider, "Posterior parietal cortex and the filtering of distractors," Proceedings of the National Academy of Sciences of the United States of America, vol. 100, no. 7, pp. 4263-4268, 2003.

[190] M. Rosanova, A. Casali, V. Bellina, F. Resta, M. Mariotti, and M. Massimini, "Natural frequencies of human corticothalamic circuits," Journal of Neuroscience, vol. 29, no. 24, pp. 7679-7685, 2009.

[191] K. McAlonan, J. Cavanaugh, and R. H. Wurtz, "Guarding the gateway to cortex with attention in visual thalamus," Nature, vol. 456, no. 7220, pp. 391-394, 2008.

[192] I. Melzer, E. Damry, A. Landau, and R. Yagev, “The influence of an auditory-memory attention-demanding task on postural control in blind persons," Clinical Biomechanics, vol. 26, no. 4, pp. 358-362, 2011.

[193] H. Burton, R. J. Sinclair, and S. Dixit, "Working memory for vibrotactile frequencies: comparison of cortical activity in blind and sighted individuals," Human Brain Mapping, vol. 31, no. 11, pp. 1686-1701, 2010.

[194] A. Garg, D. Schwartz, and A. A. Stevens, "Orienting auditory spatial attention engages frontal eye fields and medial occipital cortex in congenitally blind humans," Neuropsychologia, vol. 45, no. 10, pp. 2307-2321, 2007.

[195] O. Després, V. Candas, and A. Dufour, "Spatial auditory compensation in early-blind humans: involvement of eye movements and/or attention orienting?" Neuropsychologia, vol. 43, no. 13, pp. 1955-1962, 2005.

[196] A. H. Neuhaus, C. Urbanek, C. Opgen-Rhein et al., "Eventrelated potentials associated with Attention Network Test," International Hournal of Psychophysiology, vol. 76, no. 2, pp. 7279, 2010.

[197] A. Zani and A. M. Proverbio, "Is that a belt or a snake? Object attentional selection affects the early stages of visual sensory processing," Behavioral and Brain Functions, vol. 8, article 6, 2012.

[198] M. Stokes, R. Thompson, R. Cusack, and J. Duncan, “Top-down activation of shape-specific population codes in visual cortex during mental imagery," Journal of Neuroscience, vol. 29, no. 5, pp. 1565-1572, 2009.
[199] M. Stokes, A. Saraiva, G. Rohenkohl, and A. C. Nobre, "Imagery for shapes activates position-invariant representations in human visual cortex," NeuroImage, vol. 56, no. 3, pp. 1540-1545, 2011.

[200] A. G. De Volder, H. Toyama, Y. Kimura et al., "Auditory triggered mental imagery of shape involves visual association areas in early blind humans," NeuroImage, vol. 14, no. $1 \mathrm{I}$, pp. 129-139, 2001.

[201] S. D. Slotnick, W. L. Thompson, and S. M. Kosslyn, "Visual mental imagery induces retinotopically organized activation of early visual areas," Cerebral Cortex, vol. 15, no. 10, pp. 1570-1583, 2005.

[202] A. Vanlierde, A. G. De Volder, M. Wanet-Defalque, and C. Veraart, "Occipito-parietal cortex activation during visuo-spatial imagery in early blind humans," NeuroImage, vol. 19, no. 3, pp. 698-709, 2003.

[203] E. Mellet, N. Tzourio, F. Crivello, M. Joliot, M. Denis, and B. Mazoyer, "Functional anatomy of spatial mental imagery generated from verbal instructions," Journal of Neuroscience, vol. 16, no. 20, pp. 6504-6512, 1996.

[204] R. B. H. Tootell, N. Hadjikhani, E. K. Hall et al., "The retinotopy of visual spatial attention," Neuron, vol. 21, no. 6, pp. 1409-1422, 1998.

[205] J. B. Hopfinger, M. H. Buonocore, and G. R. Mangun, "The neural mechanisms of top-down attentional control," Nature Neuroscience, vol. 3, no. 3, pp. 284-291, 2000.

[206] H. Zhou and R. Desimone, "Feature-based attention in the frontal eye field and area V4 during visual search," Neuron, vol. 70, no. 6, pp. 1205-1217, 2011.

[207] A. D. Cate, T. J. Herron, E. W. Yund et al., "Auditory attention activates peripheral visual cortex," PLOS ONE, vol. 4, no. 2, article e4645, 2009.

[208] N. Kanwisher and E. Wojciulik, "Visual attention: insights from brain imaging," Nature Reviews Neuroscience, vol. 1, no. 2, pp. 91-100, 2000.

[209] C.-T. Wu, D. H. Weissman, K. C. Roberts, and M. G. Woldorff, "The neural circuitry underlying the executive control of auditory spatial attention," Brain Research, vol. 1134, no. 1, pp. 187-198, 2007.

[210] D. N. Saito, K. Yoshimura, T. Kochiyama, T. Okada, M. Honda, and N. Sadato, "Cross-modal binding and activated attentional networks during audio-visual speech integration: a functional MRI study," Cerebral Cortex, vol. 15, no. 11, pp. 1750-1760, 2005.

[211] A. Degerman, T. Rinne, J. Salmi, O. Salonen, and K. Alho, "Selective attention to sound location or pitch studied with fMRI," Brain Research, vol. 1077, no. 1, pp. 123-134, 2006.

[212] C. E. Wakefield, J. Homewood, and A. J. Taylor, "Cognitive compensations for blindness in children: an investigation using odour naming," Perception, vol. 33, no. 4, pp. 429-442, 2004.

[213] Q. Chen, M. Zhang, and X. Zhou, "Spatial and nonspatial peripheral auditory processing in congenitally blind people," NeuroReport, vol. 17, no. 13, pp. 1449-1452, 2006.

[214] B. Forster, A. F. Eardley, and M. Eimer, "Altered tactile spatial attention in the early blind," Brain Research, vol. 1131, no. 1, pp. 149-154, 2007.

[215] B. Röder, U. M. Krämer, and K. Lange, "Congenitally blind humans use different stimulus selection strategies in hearing: an ERP study of spatial and temporal attention," Restorative Neurology and Neuroscience, vol. 25, no. 3-4, pp. 311-322, 2007.

[216] K. E. Weaver and A. A. Stevens, "Attention and sensory interactions within the occipital cortex in the early blind: an 
fMRI study," Journal of Cognitive Neuroscience, vol. 19, no. 2, pp. 315-330, 2007.

[217] H. Burton, "Visual cortex activity in early and late blind people," Journal of Neuroscience, vol. 23, no. 10, pp. 4005-4011, 2003.

[218] A. P. Saygin and M. I. Sereno, "Retinotopy and attention in human occipital, temporal, parietal, and frontal cortex," Cerebral Cortex, vol. 18, no. 9, pp. 2158-2168, 2008.

[219] F. Moradi, G. T. Buračas, and R. B. Buxton, "Attention strongly increases oxygen metabolic response to stimulus in primary visual cortex," NeuroImage, vol. 59, no. 1, pp. 601-607, 2012.

[220] J. A. Brefczynski and E. A. DeYoe, "A physiological correlate of the "spotlight" of visual attention," Nature Neuroscience, vol. 2, no. 4, pp. 370-374, 1999.

[221] G. Deshpande, S. LaConte, G. A. James, S. Peltier, and X. Hu, "Multivariate granger causality analysis of fMRI data," Human Brain Mapping, vol. 30, no. 4, pp. 1361-1373, 2009.

[222] S. Peltier, R. Stilla, E. Mariola, S. LaConte, X. Hu, and K. Sathian, "Activity and effective connectivity of parietal and occipital cortical regions during haptic shape perception," Neuropsychologia, vol. 45, no. 3, pp. 476-483, 2007.

[223] G. Deshpande, X. Hu, S. Lacey, R. Stilla, and K. Sathian, “Object familiarity modulates effective connectivity during haptic shape perception," NeuroImage, vol. 49, no. 3, pp. 1991-2000, 2010. 

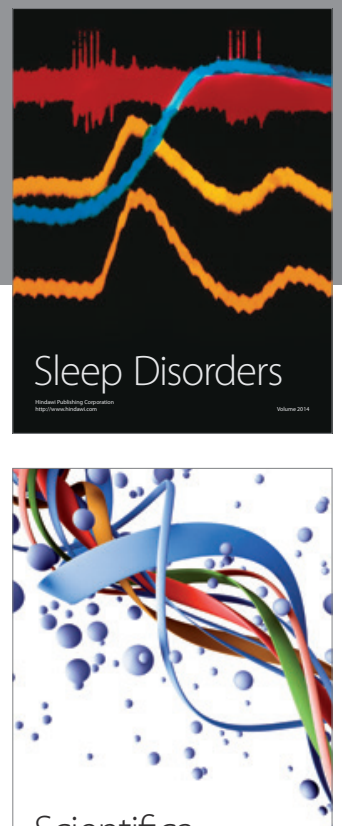

Scientifica
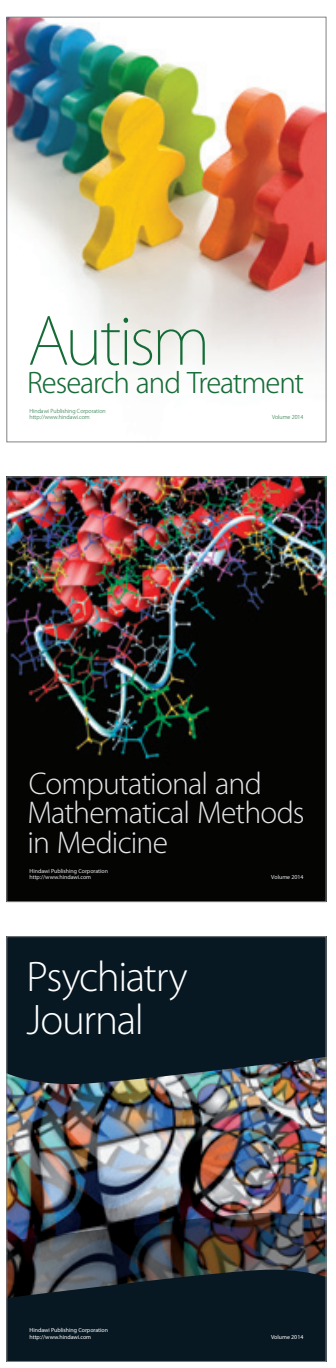
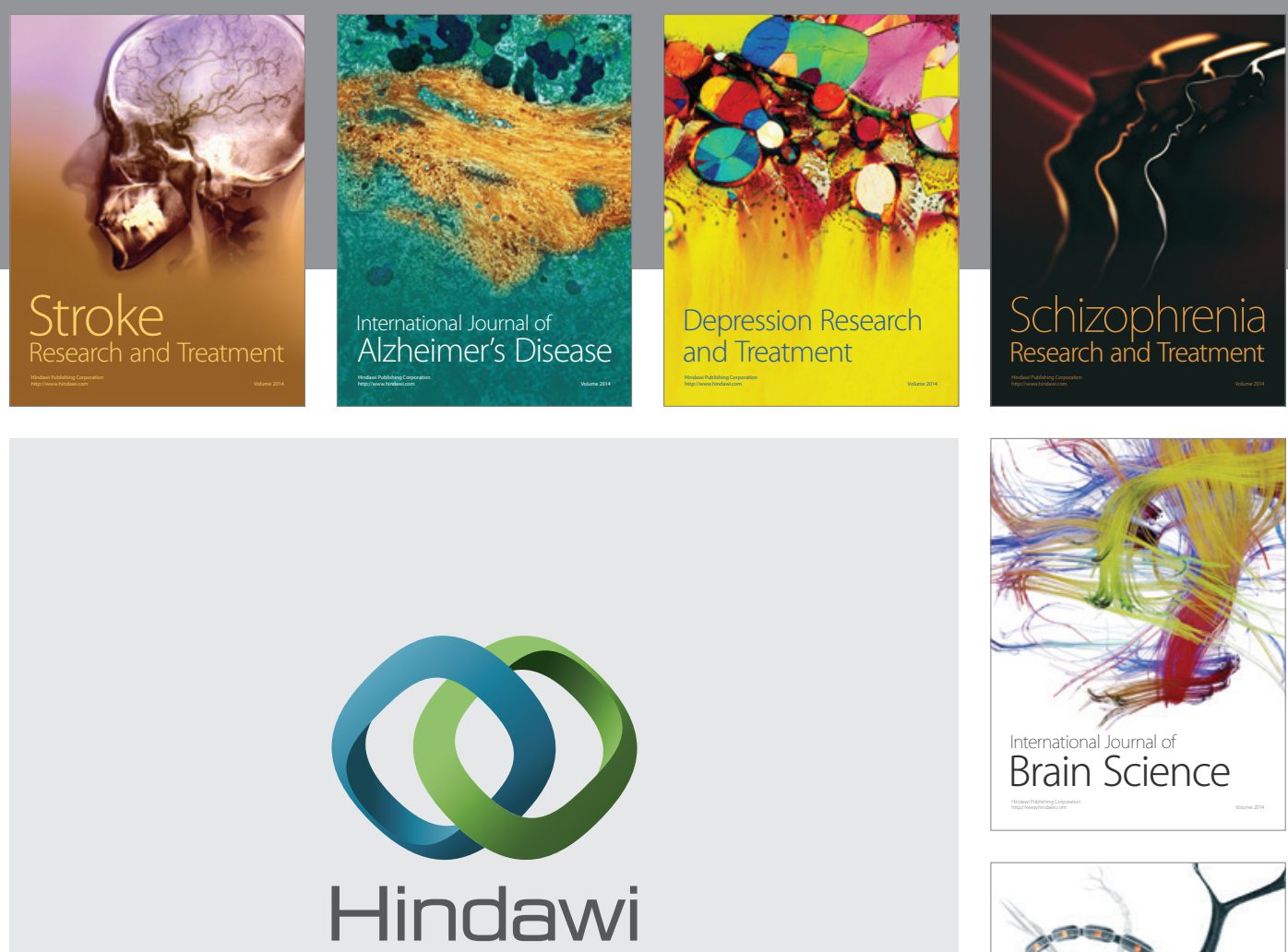

Submit your manuscripts at

http://www.hindawi.com
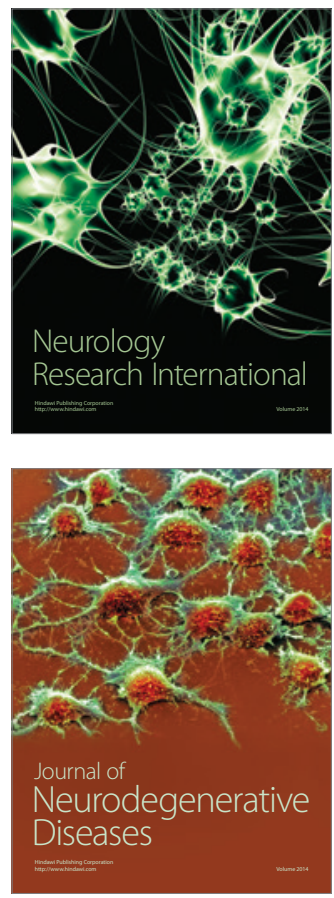

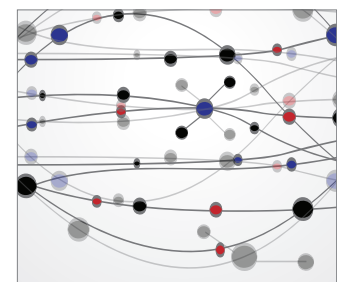

The Scientific World Journal
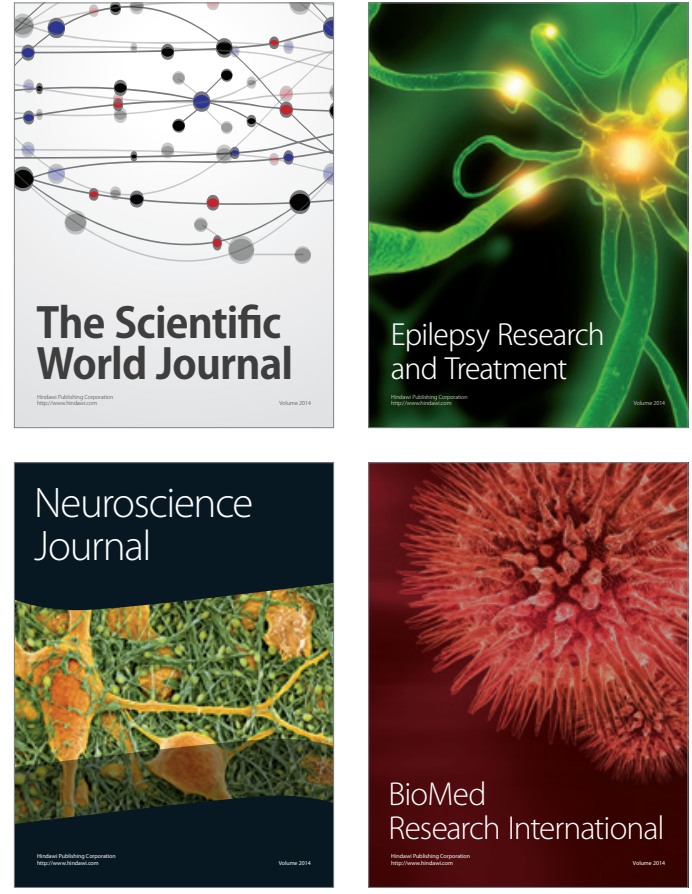

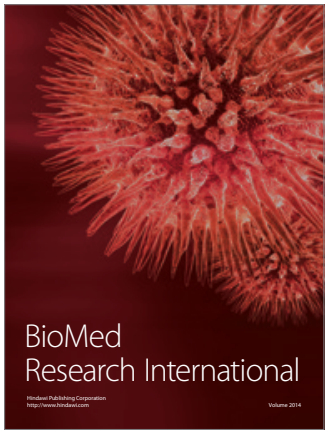

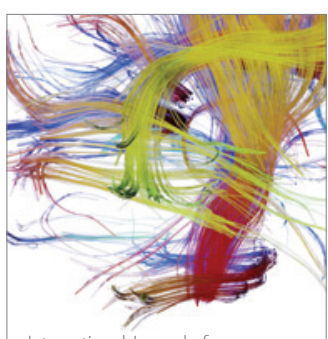

Brain Science

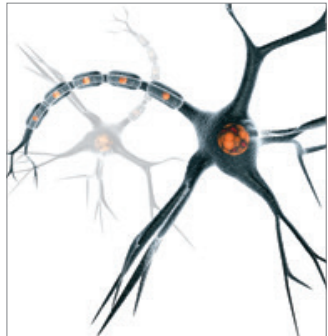

Neural Plasticity
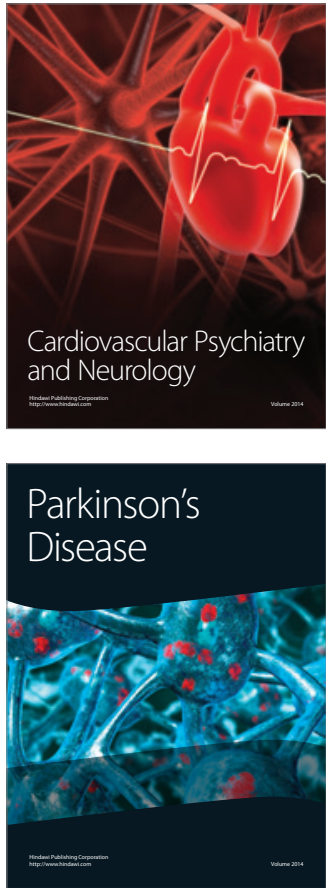